\title{
The relationship between demographic groups and perception of inclusion in a South African organisation
}

\author{
P. Daya and K.A. April* \\ Graduate School of Business, University of Cape Town, Private Bag X3, Rondebosch 7700, Republic of South Africa \\ preeya.daya@gsb.uct.ac.za \\ Graduate School of Business, University of Cape Town \& Ashridge Business School, United Kingdom \\ kurt.april@gsb.uct.ac.za \& kurt.april@ashridge.org.uk
}

\begin{abstract}
The extreme demographic-role misrepresentation within organisations is a key business and societal issue in postApartheid South Africa. This research relates to deepening the understanding about the perception of inclusion with respect to demographic groups such as race/ethnicity, gender, age, tenure, religion, sexual orientation, disability, position/grade, department, as well as site location. Secondly, it seeks to understand which groups perceive inclusion less positively than other groups, when we consider the occurrence of all the groups simultaneously using structural equation modelling (SEM).
\end{abstract}

Keywords: diversity, inclusion, demographics, groups, perception, South Africa

\section{Definitions}

'Diversity' is an employee base-representative of the differences apparent in the broader society (Wah, 1999). These include both visible (surface-level) and non-visible (deep-level) characteristics (Milliken \& Martins, 1996; Pelled, Eisenhart \& Xin, 1999).

'Inclusion' refers to empowering environments of difference, where people can be themselves, comfortably contributing their full selves and all the ways in which they differ from others, and respecting others' without making it difficult for others' to be their full selves (April, Ephraim \& Peters, 2012).

A diverse and inclusive environment therefore represents both the commitment to achieving diverse representation at all levels of the organisation and the creation of an inclusive culture where employees area able to be respected and valued for their individual unassimilated contribution.

*To whom all correspondence should be addressed.

\section{Introduction}

In the context of this research, diversity in organisations refers to the representation of historically disadvantaged individuals and all other forms of visible and non-visible characteristics (age, sexual orientation, education, etc.). Inclusion refers to the individual or group experience of being accepted and respected in the organisation. Understanding whether perception of inclusion differs between groups, provides an indication of which groups perceive inclusion less positively than other groups. This informs where intervention action should lie within organisations. Mor Barak and Cherin (1998) and Mor Barak and Levin (2002) suggest that employees who perceive inclusion positively are more likely to remain employed at a company than employees who perceive inclusion less positively. The implication for this research is that if designated groups ${ }^{1}$ perceive inclusion less positively than

\footnotetext{
${ }^{1}$ 'Designated groups' are Blacks, Females (White and Others) and Disabled individuals. 'Black people' is a generic term which includes Blacks, Coloureds (formal mixed-race category in South Africa) and Indian. These
}

other groups, their representation is not likely to grow in organisations because they are likely to leave companies faster than included, well-represented groups. This is an important consideration in South Africa, where Black, Indian, Coloured, all Women and Disabled individuals are underrepresented in the workplace (Commission for Employment Equity, 2010).

The Commission for Employment Equity (2010) recently reported that while $74.1 \%$ of South Africa's economically active population (EAP) is Black, individuals from this group who work in the private sector account for $18.5 \%$ of top management, $21.8 \%$ of senior management and $36.3 \%$ of professionally skilled employees. Comparatively, White South Africans constitute $11.9 \%$ of the EAP, but account for $65.4 \%$ of top management, $59.1 \%$ of senior management and $42.3 \%$ of professionally skilled employees. Women constitute $45.4 \%$ of the EAP, and account for $19.1 \%$ of top management, $28.2 \%$ of senior management and $43 \%$ of

groups were marginalised during Apartheid, and as such are underrepresented at certain levels within South African organisations. 
professionally qualified employees (Commission for Employment Equity, 2012).

In light of this context, the following research question is explored in this study: What is the relationship between demographic characteristics and perception of inclusion? This question contributes to practice through exploring whether group characteristics such as age, race or gender affect the perception of inclusion of that group. It should be noted here that 'race' is a contested sociological construct (Montagu, 1974). Montagu (1974: 62) emphatically claimed that 'race' is a meaningless construct based on unexamined facts and unjustifiable generalisations, and which does not realistically define the continuous variations in biology between human beings. The researchers' own preference is for the terms 'ethnicities' or 'racio-ethnic groups' (Cox \& Nkomo, 1990) which highlights historicosocial experiences and shared social identities - however, given that the formal classifications in the South African workplace is 'race-based' and national data is captured based on 'race', we chose to (reluctantly) use this term in our surveys and write-up. Understanding whether perceptions of diversity and inclusion can be attributed to a specific group characteristic allows managers and researchers to understand which groups perceive inclusion less positively. This understanding enables practitioners and the research community to develop and implement measures to shift perceptions of exclusion in favour of inclusive environments that contribute to potential high performance.

This study differs from previous studies in three ways. Firstly this study is conducted in South Africa where the demographic constitution of groups are largely dissimilar to the US and Israeli contexts examined in these studies. Secondly, this research uses a validated inclusion scale called the InclusionIndex ${ }^{\mathrm{TM}}$ survey (April \& Blass, 2010), designed and run by a company called Performance Through Inclusion. Third, the 'usual' demographic characteristics examined in studies (race, gender, age, sexual orientation, disability, education, job categories, tenure) are somewhat different in this study which includes race, gender, age, tenure, sexual orientation, disability, position/grade, department, site location and religion. The following hypotheses are tested:

\section{$H_{01}$ : There is no relationship between gender and} perception of inclusion.

$H_{1}$ : There is a positive correlation between gender and perception of inclusion.

$H_{02}$ : There is no relationship between race and perception of inclusion.

$\mathrm{H}_{2}$ : There is a positive correlation between race and perception of inclusion.

$H_{03}$ : There is no relationship between position and perception of inclusion.

$\mathrm{H}_{3}$ : There is a positive correlation between position and perception of inclusion.

\begin{abstract}
$H_{04}:$ There is no relationship between sexual orientation and perception of inclusion.

$\mathrm{H}_{4}$ : There is a positive correlation between sexual orientation and perception of inclusion.
\end{abstract}

\section{$H_{05}$ : There is no relationship between religion and perception of inclusion. \\ $H_{5}$ : There is a positive correlation between religion and perception of inclusion.}

\section{$H_{06}$ : There is no relationship between geographic location and perception of inclusion. \\ $H_{6}$ : There is a positive correlation between geographic location and perception of inclusion.}

\section{$H_{07}$ : There is no relationship between the department membership and perception of inclusion. \\ $H_{7}$ : There is a positive correlation between the department membership and perception of inclusion.}
$H_{08}:$ There is no relationship between tenure and perception of inclusion.
$H_{8}$ : There is a positive correlation between tenure and perception of inclusion.

\section{$H_{09}$ : There is no relationship between age and perception of inclusion. \\ $H_{9}$ : There is a positive correlation between age and perception of inclusion.}

\section{$H_{010}$ : There is no relationship between disability and perception of inclusion. \\ $H_{10}$ : There is a positive correlation between disability and perception of inclusion.}

\section{Literature review}

The primary element of a multicultural organisation (Cox, 1991) is a heterogeneous environment that is committed to not just the representation, but the inclusion of diverse individuals. While many South African organisations have diversity management strategies, these strategies are usually limited to include a transformation of demographics that is aligned to employment equity reporting requirements Booysen and Nkomo (2010). Miller and Katz (2002) and Roberson (2006) suggest that inclusion is a sense of belonging, feeling respected, valued for who you are, feeling a level of supportive energy and commitment from others that enables peak performance. Daya (2010) suggests that inclusion is a shift in the organisational culture, and is a process which engages each individual and makes him or her feel valued and essential to the success of the organisation.

Several researchers (Mor Barak \& Levin, 2002; Findler, Wind \& Mor Barak, 2001; Mor Barak, Nissley \& Levin, 2001; Mor Barak, 2000; Pelled, Ledford \& Morman, 1999) have explored the relationship between various diversity characteristics and perceptions of inclusion. Mor Barak and Levin (2002) suggest that there is further need for 
investigation of diversity characteristics such as religion, age, physical ability and accent. A further reason for testing these hypotheses comes from Miller (1998: 157), who suggests that organisations need to 'find new ways to maximise each person's ability to contribute and add value'. Understanding whether groups of people perceive inclusion or exclusion is critical to understanding where the issues lie, and ensures that interventions are focused on the correct issues.

Pelled et al. (1999a) find that employees who are different from their work unit in race and gender tend to be less included compared to their co-workers. Further, Pelled et al. (1999a) find that individuals who are dissimilar from their groups, but have more tenure or education, show higher levels of inclusion than their colleagues. In an inclusion study conducted in California and Israel, Findler et al. (2001) find that age and gender affects perception of inclusion. In the California study, ethnicity, education and job category emerged as additional factors affecting inclusion.

While there are studies which examine the relationship between demographic factors and variables such as performance or innovation, those are not directly relevant to this research.

\section{Methodology}

A quantitative analysis was conducted to explore the inclusion factors which influenced perception of inclusion within, and between, the demographic groups. The inclusion and demographic data were collected using a survey which was run in a division of a large multinational in South Africa. The division was one of five sales and distribution units which operates in the Eastern- and Western Cape, located within the southernmost region of South Africa. The division is a sizeable operation, with an operating turnover of approximately R4 billion (approx. $\$ 600$ million) per year. It operates as a decentralised business unit, headed by a general manager and executive team who run the operation from sites distributed throughout the Eastern- and Western Cape. Employee headcount ranges between 400 and 425 permanent employees, and uses approximately the same number of contract staff.

Perception of inclusion and demographic classification of respondents were obtained using a survey instrument called the InclusionIndex ${ }^{\mathrm{TM}}$ survey. The survey was developed by Joerg Schultz (University of Hertfordshire, UK), Mark Slaski (University of Hertfordshire, UK), Eddie Blass (Swinburne University of Technology, Australia) and Kurt April (University of Cape Town, SA and Ashridge, UK). The ten factors were determined through a rigorous academic process, which involved correlational analysis and principal component analysis (April \& Blass, 2010). The tool is owned by a company called Performance Through Inclusion, which administers the roll-out and analysis of the tool across numerous industries globally, in the private and public sector. The survey contains 73 questions under the following ten categories: 'Senior Managers', 'Immediate Manager', 'Values', 'Recruitment', Promotion Progression and Development', 'Fitting In', 'Bullying and Harassment', 'Dialogue', 'Organisational Belonging' and 'Emotional Well-Being'.

\section{Sample}

The survey response rate was $64 \%$ with 259 out of 403 employees completing the survey. Only 248 of the 259 surveys were able to be used for the analysis because 11 were unusable due to incomplete information. The demographic groups were customised for this research and were categorised as follows: Race was categorised into White, Black, Coloured and Indian, gender into male and female, age into <20, 21-29, 30-39, 40-40, 50-59, 60+. Tenure was categorised as: $0-2$ years, $2.1-4$ years, 4.1-6 years, 6.1-8 years and $8+$ years, sexual orientation into homosexual/bi-sexual or heterosexual; religion into Catholic, Anglican, Protestant, Charismatic, Traditional African, Hindu, Muslim, Christian, Other. Organisational position into 1 (lowest grade), 2, 3, 4 and 5 (highest grade); department into sales, operations and support, and, location into location 1 , location 2 , location 3 , location 4 and location 5. In the defined demographic categories such as race, age and tenure, the numbers suggest that the sample generally reflects the research population across the various demographic groups. The survey data proved to have high internal consistency, with a Cronbach's alpha of 0.964 between the inclusion variables of components one to nine. Factor 10, emotional well-being was excluded because the Cronbach's alpha for this factor was below the recommended limit of 0.60 .

\section{Analysis}

Analysis of variance (ANOVA) and structured equation modelling (SEM) techniques were used to better understand insights into the research question. Analysis of variance was used for analysis of group differences and was used to determine statistical variance between the groups (Church \& Waclawski, 1998). The test uses the F-ratio to determine the overall fit of a linear model (Field, 2005).

Govender (2003: 2) indicates that structured equation modelling is also known as simultaneous equation modelling, "whereby we hypothesise and test the simultaneous impact of a set of variables on another set or sets of variables'. This methodology was employed for two reasons. Although other multivariate techniques are useful in determining the relationship or interaction between variables, this technique enables one to combine the variables into one model and test the relationships simultaneously. Second, SEM allows us to understand whether the variance in the demographic factors is caused by variance in perception of inclusion.

Dion (2008: 366) asserts that there are numerous indices used to test model fit, "which indicates how closely the data fit the model' and determine whether the findings of the 
model are reliable and can be used. The Chi square $\left(\chi^{2}\right)$ and degrees of freedom (df) are used to determine the normed Chi Square $\left(\chi^{2} / \mathrm{df}\right)$, which should be as small as possible, but not higher than 3 according to Dion (2008: 367). The root mean square error of approximation (RMSEA) is a parsimony-adjusted index in that its formula includes a built-in correction for model complexity (Kline, 2005), and the value should be less than 0.05 . The Goodness of Fit, Comparative Fit index and Incremental Fit index explain the fit of the model, with values $>90$ indicating good model fit. The standardised root mean square residual (SRMR) is a measure of the difference between the observed and predicted correlation, and values less than 0.10 are considered favourable (Kline, 2005).

In the graphical SEM, a line with a single arrowhead represents a hypothesised direct effect of one variable on another (Kline, 2005). The relationship is described by path coefficients. These path coefficients are described by parameter estimate, measurement error and T-statistic also known as wald statistic (Simon, 2002). 'The loading of the path coefficient is considered to be significant when the tstatistic is greater than the 1.96 cut-off for $\alpha=0.05$ or a $95 \%$ confidence level' (Geldhof, Selig \& McConnell, 2008: 2).

\section{Findings}

\section{Structured equation model}

The structured equation model proved to have a moderate assessment of adequacy with a $\chi^{2}=215.15$, df of 108 , Goodness of Fit of 0.092, Comparative Fit Index of 0.95, SMSR of 0.05 and RMSEA of 0.06 .

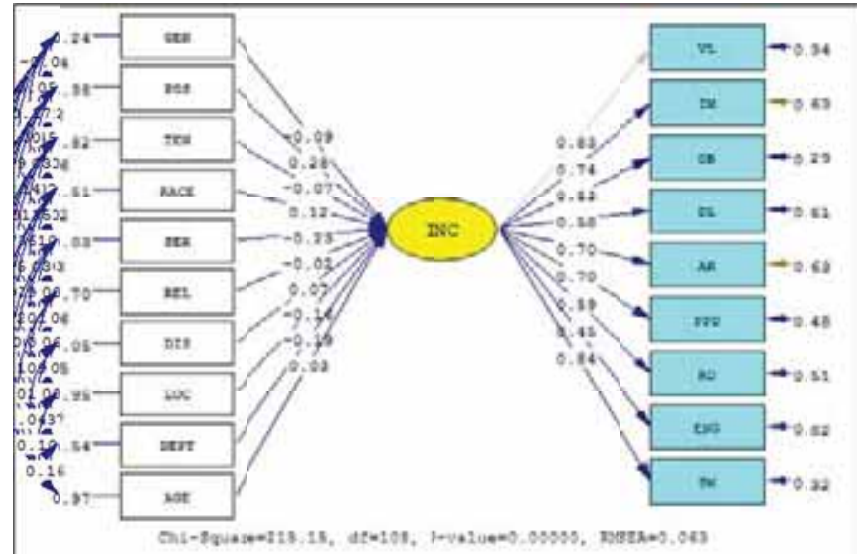

Figure 1: Model 1 - Investigating the relationship between inclusion and diversity characteristics

Kline (2005: 101) mentions that when trimming and building models, it is necessary to define a free parameter, which the program uses 'to estimate all other model parameters while holding this path coefficient constant'. Construct 'Organisational Values' was used as a free parameter in order to stabilise the model. As the values listed in Table 1 were significant, and the model fit fell within the required range, perception of inclusion was seen to be accounted for by the individual's perception of the organisation's values, the relationship the individual has with his/her immediate line managers, his/her perception of organisational belonging, dialogue about diversity and inclusion in the organisation, whether employees felt accepted and respected in their work environment, perception of promotion, progression and development, actual representation of diverse individuals in the organisation, level of individual engagement, and importance of diversity and inclusion to senior managers.

Table 1: Standardised solution and T values between inclusion variables and inclusion (latent) in Model 1

\begin{tabular}{lcccccc}
\hline & $\begin{array}{l}\text { Org } \\
\text { Values }\end{array}$ & $\begin{array}{l}\text { Immediate } \\
\text { Mgr }\end{array}$ & $\begin{array}{l}\text { Org } \\
\text { Belong. }\end{array}$ & Dialogue & $\begin{array}{l}\text { Acceptance } \\
\text { and Respect }\end{array}$ & $\begin{array}{l}\text { Prom, } \\
\text { Prog } \\
\text { and } \\
\text { Dev. }\end{array}$ \\
\hline $\begin{array}{l}\text { Standardised } \\
\text { solution }\end{array}$ & 0,83 & 0,74 & 0,53 & 0,58 & 0,70 & $\begin{array}{l}\text { Rep. } \\
\text { Diversity } \\
\text { Mgt. }\end{array}$ \\
\hline T value & & 11,46 & 11,81 & 9,69 & 11,09 & 0,70 \\
\hline
\end{tabular}

When exploring the relationship between individual perception of inclusion and demographic factors (Table 2), the model suggested position in the company, racial background of the individual, location employee is based at and the department the employee is based in significantly affects perception of inclusion. The model suggested that individual perception of inclusion was not seen to be affected by gender, tenure, age, sexual orientation, religion and disability.

Table 2: Standardised solution and T values between the demographic factors and inclusion in Model 1

\begin{tabular}{lcccccccccccccc}
\hline & Gender & Age & Position & Tenure & Race & $\begin{array}{l}\text { Sex. } \\
\text { Orientation }\end{array}$ & Religion & Disability & Location & Department \\
\hline $\begin{array}{l}\text { Standardised } \\
\text { solution }\end{array}$ & $-0,09$ & 0,03 & 0,28 & $-0,07$ & 0,12 & $-0,23$ & $-0,02$ & 0,07 & $-0,16$ \\
\hline T value & $-0,69$ & 0,39 & 4,71 & $-1,39$ & 2,27 & $-0,64$ & $-0,67$ & 0,23 & $-3,24$ & $-2,02$ & \\
\hline
\end{tabular}




\section{Analysis of Variance}

\section{Race}

Analysis of variance indicated significant relationships between the race of the employee and their perception of senior management $(\mathrm{F}=4.34 ; \quad \mathrm{p}=0.00)$, immediate management $(\mathrm{F}=3.12 ; \mathrm{p}=0.023)$, perception of being valued $(\mathrm{F}=2.85 ; \mathrm{p}=0.03)$, experience of fitting in $(\mathrm{F}=5.81 ; \mathrm{p}=0.00)$, and perception of being bullied and harassed $(\mathrm{F}=5.33$; $\mathrm{p}=0.00$ ). Overall, these results suggested that race was a determinant of a few important organisational factors which related to the individual's perception of inclusion. More specifically, it was clear that in all instances, White and Indian employees tended to have much more positive experiences in terms of fitting into the institution, they had positive relationships with senior managers and their immediate managers, and were less likely to feel bullied or harassed. In contrast, Coloured and in particular African Black employees were likely to have either experienced or perceived the converse: they viewed their relationships with their immediate managers and senior managers to be more problematic, were less likely to fit into the organisation and were likely to believe that they were prone to being bullied and harassed.

The post hoc comparisons of the differences between each of the racial groups within the categories indicated that the differences were most pronounced and statistically significant for African Black employees when compared to White employees, as well as for Coloured employees when compared to White employees. In other words, not only were White employees likely to have more qualitatively positive experiences in the company, but these differences are also quantitatively substantive.

\section{Gender}

The ANOVA found no significant relationship between gender and inclusion on the aggregated scores of the categories, which suggests that there is no relationship between gender and an individual's perception of inclusion. In a second survey run in the research organisation measuring organisational effectiveness, the mean scores of men and women were the same, suggesting that perception of organisational effectiveness in this organisation is equitable.

\section{Position}

Analysis of variance showed that position in the company has a statistically significant effect on the perception of feeling valued in the organisation $(\mathrm{F}=8.08 ; \mathrm{p}=0.00)$, immediate management $(\mathrm{F}=6.30 ; \quad \mathrm{p}=0.00), \quad$ senior management $(\mathrm{F}=8.13 ; \mathrm{p}=0.00)$, perception of equitable promotion, progression and development $(\mathrm{F}=3.84 ; \mathrm{p}=0.00)$, experience of fitting in $(\mathrm{F}=5.69 ; \mathrm{p}=0.00)$, being bullied and harassed $(\mathrm{F}=9.02 ; \quad \mathrm{p}=0.00)$ and the perception of organisational belonging $(\mathrm{F}=3.51 ; \mathrm{p}=0.00)$.
The results indicated that when looking at the individual's perception of senior management, feeling valued in the organisation, perception of promotion as well as progression and development in the company; the higher the grade level of the employee, the higher his/her perception of these inclusion measures was. Senior- and junior management experienced the highest sense of fitting in and organisational belonging. Employees between shop floor level and junior management level, and shop floor employees, perceived themselves to be targets of bullying and harassment and perceived their relationship with their immediate managers to be the poorest.

The post hoc comparisons of the differences between groups indicated that differences were most pronounced and statistically significant when comparing shop floor individuals to other grade groupings. Employees at this level experienced the most bullying and harassment, and did not experience a sense of fitting in and organisational belonging. Their perception of their immediate managers was poor, relative to the experience of other groups, and their perception of being valued by the organisation was low compared to the experiences of other groups. Shop floor employees therefore felt significantly less included than employees at other grade levels.

\section{Sexual orientation}

The analysis of variance did not support this and showed significant results between sexual orientation and organisational belonging $(\mathrm{F}=3.92 ; \mathrm{p}=0.02)$ and senior management $(\mathrm{F}=3.65 ; \mathrm{p}=0.02)$. The results suggested that heterosexual employees experienced a significantly higher sense of organisational belonging than homosexual individuals, and perceived senior management more positively than homosexual individuals did.

\section{Religion}

Analysis of variance indicated that there was a statistical relationship between religion and fitting in $(\mathrm{T}=2.02$; $\mathrm{p}=0.04$ ). Groups that experience a high sense of fitting in were Protestants and Christians. Hindus and Muslim employees experienced fitting in less positively than other groups. Post hoc comparisons of differences between groups indicated that the difference between groups is most pronounced between Hindus and Catholics, and Hindus and Anglicans. This indicated that religion does have some bearing on an employee's perception of fitting into an organisation.

\section{Geographic location}

Analysis of variance of the averages of the categories and location, however, indicated significant relationships between the site that the employees worked at and their perception of feeling valued in the organisation $(\mathrm{F}=3.9$; $\mathrm{p}=0.00)$, experience of a fair recruitment process $(\mathrm{F}=5.89$; $\mathrm{p}=0.00$ ), perception of the senior management in the organisation $(\mathrm{F}=3.37 ; \mathrm{p}=0.01)$, and experience of being 
bullied and harassed $(\mathrm{F}=2.48 ; \mathrm{p}=0.044)$. As the sites were geographically dispersed and led by different senior managers, it is expected that inclusion would differ according to the local culture created there. Inclusion, as measured by these variables, was perceived to be the highest at a site that was headed by a Black senior manager who valued and prioritised an inclusive culture. The post hoc comparisons of the differences between groups indicated that the differences were most pronounced, and statistically significant, when comparing this site to other sites in terms of the categories listed above. This suggested that the leadership style, and perhaps even the race, of the senior manager could have had some influence over the individuals' perception of inclusion.

\section{Department}

The one way analysis of variance supported this finding, but also showed significant relationships between the department an individual works in and his/her perception of senior management $(\mathrm{F}=4.36 ; \mathrm{p}=0.014)$ and their immediate managers $(\mathrm{F}=3.23 ; \mathrm{p}=0.04)$, his/her experience of feeling valued by the organisation $(\mathrm{F}=5.03 ; \mathrm{p}=0.00)$, perception of the recruitment process $(\mathrm{F}=4.48 ; \mathrm{p}=0.01)$, experience of fitting into the organisation $(\mathrm{F}=3.86 ; \mathrm{p}=0.22)$, of being bullied and harassed $(\mathrm{F}=4.31 ; \mathrm{p}=0.22)$, and his/her experience of organisational belonging $(\mathrm{F}=2.48$; $\mathrm{p}=0.086)$. Sales employees had the most positive experience in terms of these measures, followed by support staff. Operations staff had less positive views or experiences on all categories except fitting in, where support staff felt less adapted than both groups. This might have been because the business was centred on the sales and operations functions, while the support staff held a support function to these groups and therefore had less of a group identity.

\section{Tenure}

In the analysis of variance, tenure showed a non-significant relationship between individual perception of inclusion and length of service.

\section{Age}

One-way analysis of variance tests indicated significant relationships between the age of the individual and his/her perception of senior management $(\mathrm{F}=3.46 ; \mathrm{p}=0.01)$, immediate management $(\mathrm{F}=5.05 ; \mathrm{p}=.000)$, perception of feeling valued by the organisation $(F=6.09 ; p=0.00)$, view of promotion, progression and development in the organisation $(\mathrm{F}=2.99 ; \mathrm{p}=0.03)$, experience of fitting in $(\mathrm{F}=2.92 ; \mathrm{p}=0.03)$, and of being bullied and harassed $(\mathrm{F}=2.79 ; \mathrm{p}=0.04)$. The group that felt the most positively were the 30-39 year old employees, followed by 20-29 year olds. The group that felt the least positive were the 40-49 year old employees. This could have been because employees in this group have fewer options to progress than younger employees, who pursue career progression actively through acquiring qualifications and focusing on their performance. Alternatively, most employees in this category are individuals who have been operating in the operations function for many years and have little opportunity to progress outside of their area of work. The post hoc comparisons of the differences between each of the groups indicates that the differences are most pronounced and statistically significant for employees aged 40-49 when compared to employees aged 20-29, and employees aged 30-39 when compared with 40-49 year-old employees. Employees aged 40+ were more bullied and harassed than the 20-29 year olds, and felt less positively about fitting into the organisation. This indicated that younger employees were more likely to have a positive experience of the organisation than employees aged 40-49 and, to a lesser extent, employees aged $50+$.

\section{Disability}

A one-way ANOVA test indicated a significant relationship between being disabled and one's perception of being bullied and harassed in the organisation $(F=4.09 ; \mathrm{p}=0.044)$. Employees without a disability experienced less bullying and harassment than disabled individuals.

\section{Discussion of findings}

When considered simultaneously (SEM), the demographic variables which influence individual perception of inclusion are race, position/grade in a company, location employee is based at, and the employee's department. Although the ANOVA suggests a significant relationship between many of the inclusion factors and a number of group factors, this analysis does not allow us to ascertain whether the variance of the demographic group is caused by the inclusion factor. In light of this, the results of the SEM were used to accept the following hypotheses:

$H_{01}$ : There is no relationship between gender and perception of inclusion in this study.

$\mathrm{H}_{2}$ : There is a positive correlation between race and perception of inclusion in this study.

$\mathrm{H}_{3}$ : There is a positive correlation between position and perception of inclusion in this study.

$H_{04}$ : There is no relationship between sexual orientation and perception of inclusion in this study.

$H_{05}$ : There is no relationship between religion and diversity and perception of inclusion in this study.

$H_{6}$ : There is a positive correlation between geographic location and perception of inclusion in this study.

$H_{7}$ : There is a positive correlation between the department an individual works in and perception of inclusion in this study.

$H_{08}$ : There is no relationship between tenure and perception of inclusion in this study.

$H_{09}$ : There is no relationship between age and perception of inclusion in this study.

$H_{010}$ : There is no relationship between disability and perception of inclusion in this study.

The following discussion examines the findings of this research and compares them to the scant research that is 
available on the relationship between diversity characteristics and variables such as performance, innovation and team behaviour. While this question relates specifically to the relationship between demographic characteristics and diversity and inclusion, there are very few studies that have examined this relationship (Pelled et al., 1999b; Mor Barak \& Cherin, 1998; Findler et al., 2001; Mor Barak \& Levin, 2002). Comparison with these studies should be approached with caution considering the differing measures of inclusion and further, the relationships between the diversity characteristics and inclusion are not considered parsimoniously in these studies. To provide some grounds for comparison, relevant research examining the relationship between diversity characteristics and numerous variables such as performance and innovation have been examined.

Research exploring the relationship between gender and individual perception of inclusion consistently found that women perceive inclusion less positively than men (Mor Barak \& Levin, 2002; Mor Barak et al., 2001; Pelled et al., 1999b). Mathur-Helm (2004) supports this finding in her research and claims that women are still regarded as secondary to men in South African business culture, and accept secondary roles without hesitation.

April, Dreyer \& Blass (2007) state that executive careers are only available to the few women that are resilient, are willing to work extreme hours, are willing to develop appropriate informal connectedness, and who really want an executive career, albeit at a (sacrificial) price. Riach and Rich's (2002) research focused on the interaction between gender and other variables and they note that amongst applications for a job, men are twice more likely to be selected than females. These studies suggest that the work playing field is not an equitable environment, and makes the finding that there is no relationship between gender and perception of inclusion difficult to reconcile.

The relationship between race and perception of inclusion are supported by research conducted by Mor Barak and Levin (2002), Mor Barak (2000), Ibarra (1993) and Greenhaus, Parasuraman \& Wormley (1990). They are also supported by research by Riach and Rich (2002: 36), whose 'field experiments of discrimination in the marketplace have extended across 10 countries, several markets and 35 years', indicate that there is 'demonstrated pervasive and enduring discrimination against non-Whites'. Richard (2000) found that race is positively associated with companies pursing a growth strategy, but was associated with lower productivity in companies that were downsizing or companies that failed to have a clear strategy. Jackson and Joshi (2004) found that team performance was the lowest when there was a combination of high tenure, high gender and high ethnic diversity, suggesting not only that dissimilarity with regard to race negatively affects team performance, but adds to the extensive literature that heterogeneous teams affect team performance less positively than homogenous teams.

While grade or seniority was found to be a strong driver of inclusion in both the ANOVA and SEM, there are no studies to support this finding. It reasons though that senior leaders, who have the largest influence over organisational culture, are likely to feel included in cultures which they were responsible for co-creating.

While Lesbian, Gay, Bi-sexual and Transsexual (LGBT) literature is increasingly available, there are no studies which examine the perception of inclusion of this group relative to other demographic groups.

While there are no comparable studies exploring the relationship between perception of inclusion and religion, a number of academics have suggested the need for further research in this area (Jackson, Joshi \& Erhardt, 2003; Mor Barak \& Levin, 2002; Stuber, 2005). Stuber (2005) says that religious diversity is increasing, and Mor Barak and Levin (2002) suggest that an expansion of our notions of diversity be tested to include characteristics such as religion, age, physical ability and accent.

Jackson et al. (2003: 805) mention that a constraint of 'most of the arguments offered to explain the effects of readilydetected attribute diversity assume that readily-detected attributes are associated with underlying attributes, which in turn, drive behaviour'. This is likely true of the demographic variable 'location' which could be a proxy for a tacit variable such as leadership style or organisational culture. There are no comparable studies which examine the relationship between location and perception of inclusion.

While there are no studies which examine the relationship between department membership and perception of inclusion, Pearce and Randel (2004) found that employees with low mobility are likely to experience low social inclusion. This finding is consistent with the findings of the post hoc tests which suggested that employees in operations, who typically were employed at the same site in the same job for anything between 15-40 years, perceive inclusion less positively than sales employees, who change jobs more frequently. This finding is possibly related to age, which is discussed later in this section.

Research relating to tenure does not show support for the finding of this study which highlights the fact that tenure does not influence perception of inclusion. Pelled et al. (1999b) suggests that individuals with more tenure than the group average are likely to feel more included than other individuals. Zenger and Lawrence (1989) found that technical communication is improved with team tenure, which is likely to affect individual perception of inclusion positively. Ancona and Caldwell (1992) found that diversity of tenure showed a negative relationship with performance and innovation. O'Reilly, Caldwell and Barnett (1989) demonstrate that homogeneity of tenure is positively related to the group's social integration and that the aggregate social integration of the group is related to reduced individual turnover, and likely a better sense of inclusion. While these studies do not relate specifically to inclusion, they show that tenure is likely to improve social inclusion and improve technical communication, which illustrates that tenure is an important demographic consideration. 
While the results of the SEM were broadly supported by statistical significance highlighted in the ANOVA, it was surprising that the age demographic, which showed a strong relationship with perception of inclusion, did not feature as a significant variable when considered with other demographic variables. Rosen and Jerdee (1976) found that age stereotypes portrayed older employees as less able, and research by Pearce and Randel (2004), Cox and Nkomo (1992) and Rosenbaum (1984) showed that as age increases, likelihood of promotion decreases, which places this group at a disadvantage compared to younger employees. These findings suggesting age stereotypes and employment discrimination on the basis of age could be related to the findings of Findler et al. (2001) and Pelled et al. (1999b) who found that age was related to individual perception of inclusion.

While there is literature relating to the relationship between perception of diversity and inclusion and disability in schools (Norwich, 2009), and literature available between the relationship between disability and social exclusion (Clear \& Dennis, 2009), research examining the relationship between individual perception of inclusion and disability in workplaces is not yet available in the public domain.

\section{Conclusion and limitations considerations}

This study finds that there are significant similarities in the way individuals from certain groups perceive inclusion. Further, it shows that when a number of demographic characteristics are considered simultaneously (which best reflects a real life scenario where the presence of difference is not linear), the variables that are significant in affecting inclusion are race, position or seniority in a company, location a site is based at, and the department the individual works in. This suggests that perception of inclusion is not only affected by an individual's conditioning, which is manifested through their race or position in a company, but also through organisational factors such as the location of the site or department membership. This causes us to submit that, in order to create an inclusive environment, inclusion needs to be managed both at a personal and organisational/relational level.

There are a number of important limitations with this research. Firstly, this research was conducted as a case study in one, successful (multinational) South African organisation. While future research will be conducted on exploring this relationship in different contexts, it is not yet ready for comparison. Secondly, none of the comparative studies were conducted in South Africa which possibly compound the direct comparability of the results. Related to this issue of comparability, given the recent history of Apartheid in South Africa, is the fact that currently the primary transformation issues in the country are related to race, followed closely by gender and disability inequality. This context is important when examining a research question which considers all demographic variables simultaneously. Finally, this research fails to consider the intersectionality of these variables (Holvino, 2010) which could provide valuable insight into the possible inclusion/exclusion of 'sub-groups' such as Black female senior leaders who are significantly underrepresented in South African organisations (Commission for Employment Equity, 2010).

\section{References}

Ancona, D.G. \& Caldwell, D. 1992. 'Bridging the boundary: External activity and performance in organizational teams', Administrative Science Quarterly, 37: 634-665.

April, K. \& Blass, E. 2010. 'Measuring diversity practice and developing inclusion', Dimensions, 1(1): 59-66.

April, K., Dreyer, S. \& Blass, E. 2007. 'Gender impediments to the South African executive boardroom', South African Journal of Labour Relations, 31(2): 51-67.

April, K., Ephraim, N. \& Peters, K. 2012. 'Diversity management in South Africa: Inclusion, identity, intention, power and expectations', African Journal of Business Management, 6(4): 1749-1759.

Booysen, L. \& Nkomo, S. 2010. 'Employment equity and diversity management in South Africa'. In Klarsfeld, A. (Ed.). International perspectives on diversity practices at work. Cheltenham: Edward Elgar.

Church, A.H. \& Waclawski, J. 1998. Designing and using organizational surveys. New York: John Wiley \& Sons.

Clear, F. \& Dennis, C. 2009. 'E-governance, disability and inclusion'. In Budd, L. \& Harris, L. (Eds.). E-governance: Managing or governance. New York: Routledge, pp. 213236.

Commission for Employment Equity. 2010. 'The $10^{\text {th }} \mathrm{CEE}$ Annual Report'. URL: http://www.polity.org.za/article/ tenth-commission-or-employment-equity-annual-reportjuly-2010-2010-07-29. Accessed 18 August 2011.

Commission for Employment Equity. 2012. Commission for Employment Equity Annual Report 2011- 2012. Pretoria: South African Department of Labour.

Cox Jr, T.H. 1991. 'The multicultural organization', Academy of Management Executive, 5(2): 34-47.

Cox Jr, T.H. \& Nkomo, S.M. 1992. 'Candidate age as a factor in promotability ratings', Public Personnel Management, 21(2): 197-210.

Cox, T.H. \& Nkomo, S.M. 1990. 'Invisible men and women: A status report on race as a variable in organization behavior research', Journal of Organizational Behavior, 11: 419-431.

Daya, P. 2010. 'An investigation into the relationship between diversity, inclusion and individual performance.' 
Unpublished $\mathrm{PhD}$ dissertation. Graduate School of Business, University of Cape Town.

Dion, P. 2008. 'Interpreting structural equation modelling results: A reply to Martin and Cullen', Journal of Business Ethics, 83(3): 365-368.

Field, A. 2005. Discovering statistics using SPSS $\left(2^{\text {nd }}\right.$ Edition). London: Sage.

Findler, L., Wind, L.H. \& Mor Barak, M.E. 2001. 'Diversity, inclusion, and commitment in organizations: International empirical explorations', The Journal of Behavioral and Applied Management, 2(2): 70-91.

Geldhof, G.J., Selig, J.P. \& McConnell, E.K. 2008. 'Interpreting lisrel output'. URL: http://www.quant. ku.edu/pdf/Interpreting\%20LISREL\%20Output.pdf Accessed 16 November 2011.

Greenhaus, J.H., Parasuraman, S. \& Wormley, W.M. 1990. 'Effects of race on organizational experience, job performance evaluations, and career outcomes', Academy of Management Journal, 33(1): 64-86.

Govender, R. 2003. 'Introduction to simultaneous equations modelling'. Unpublished manuscript. Cape Town: University of Cape Town.

Holvino, E. 2010. 'Intersections: The simultaneity of race, gender and class in organization studies', Gender, Work \& Organization, 17(3): 248-277.

Ibarra, H. 1993. 'Personal networks of women and minorities in management: A conceptual framework', Academy of Management Review, 18(1): 56-87.

Kline, R.B. 2005. Principles and practice of structural equation modelling. ( $2^{\text {nd }}$ Edition). New York: The Guilford Press.

Jackson, S.E. \& Joshi, A. 2004. 'Diversity in social context: A multi-attribute, multilevel analysis of team diversity and sales performance', Journal of Organizational Behaviour, 25(6): 675-702.

Jackson, S.E., Joshi, A. \& Erhardt, N.L. 2003. 'Recent research on team and organizational diversity: SWOT analysis and implications', Journal of Management, 29(6): 801-830.

Mathur-Helm, B. 2004. 'Equal opportunity and affirmative action for South African women: A benefit or barrier?' Women in Management Review, 20(1): 56-71.

Miller, F. A. 1998. 'Strategic culture change: The door to achieving high performance and inclusion', Public Personnel Management, 27(2): 151-160.
Miller, F.A. \& Katz, J.H. 2002. The inclusion breakthrough: Unleashing the real power of diversity. San Francisco: Berrett-Koehler Publishers.

Milliken, F.J. \& Martins, L.L. 1996. 'Searching for common threads: Understanding the multiple effects of diversity in organization groups', Academy of Management Review, 21(2): 402-433.

Montagu, A. 1974. Man's most dangerous myth: The fallacy of race. New York: Oxford University Press.

Mor Barak, M.E. 2000. 'The inclusive workplace: An ecosystems approach to diversity management', Social Work, 45(4): 339-353.

Mor Barak, M.E. \& Cherin, D.A. 1998. 'A tool to expand organizational understanding of workforce diversity: Exploring a measure of inclusion-exclusion', Administration in Social Work, 22(1): 47-64.

Mor Barak, M.E. \& Levin, A. 2002. 'Outside of the corporate mainstream and excluded from the work community: A study of diversity, job satisfaction and wellbeing', Community, Work \& Family, 5(2): 133-157.

Mor Barak, M.E., Nissly, J.A. \& Levin, A. 2001. 'Antecedents to retention and turnover among child welfare, social work, and other human service employees: What can we learn from past research? A review and meta-analysis', Social Service Review, 75(4): 625-661.

Norwich, B. 2009. Dilemmas of difference, inclusion and disability: International perspectives and future directions. New York: Routledge.

O'Reilly, G.A.I., Caldwell, D. \& Barnett, W. 1989. 'Work group demography, social integration, and turnover', Administrative Science Quarterly, 34(1): 21-37.

Pearce, J.L. \& Randel, A.E. 2004. 'Expectations of organizational mobility, workplace social inclusion, and employee job performance', Journal of Organizational Behavior, 25(1): 81-98.

Pelled, L.H., Eisenhardt, K.M. \& Xin, K.R. 1999. 'Exploring the black box: An analysis of work group diversity, conflict, and performance', Administrative Science Quarterly, 44: 1-28.

Pelled, L.H., Ledford, J.G.E. \& Mohrman, S.A. 1999. 'Demographic dissimilarity and workplace inclusion', Journal of Management Studies, 36(7): 1013-1030.

Republic of South Africa. 1998. 'Employment Equity Act, no. 55', Government Gazette 19370. Pretoria: The Government Printer.

Riach, P.A. \& Rich, J. 2002. 'Field experiments of discrimination in the market place', The Economic Journal, 112(483): 480-516. 
Richard, O.C. 2000. 'Racial diversity, business strategy, and firm performance: A resource-based view', Academy of Management Journal, 43(2): 164-177.

Roberson, Q.M. 2006. 'Disentangling the meanings of diversity and inclusion in organizations', Group and Organization Management, 31(2): 212-236.

Rosen, B. \& Jerdee, T.H. 1976. 'The nature of job-related age stereotypes', Journal of Applied Psychology, 61(2): 180183.

Rosenbaum, J.E. 1984. Career mobility in a corporate hierarchy. Orlando, Florida: Academic Press.

Simon, S. 2002. 'What is a t statistic?' URL: http://www.childrens-mercy.org/stats/definitions/tstat.htm. Accessed 16 July 2011.

Stuber, M. 2005. 'Business case for diversity: Push and pull factors'. URL: http://www.europeandiversity.com/downloads/Diversity-Business-Case-EN.pdf . Accessed 13 June 2011.

Wah, L. 1999) 'Diversity at Allstate', Management Review, 88(7): 24-30.

Zenger, T.R. \& Lawrence, B.S. 1989. 'Organizational demography: The differential effects of age and tenure distributions on technical communication', Academy of Management Journal, 32(2): 353-376. 